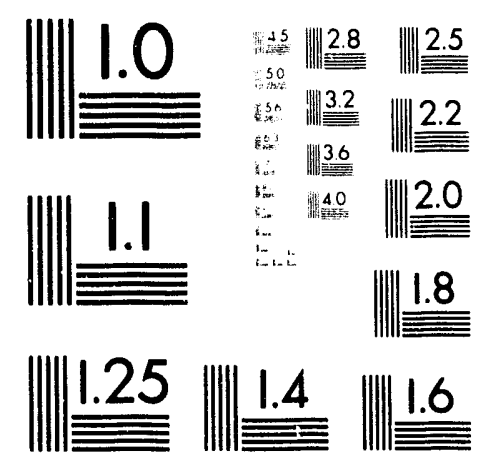



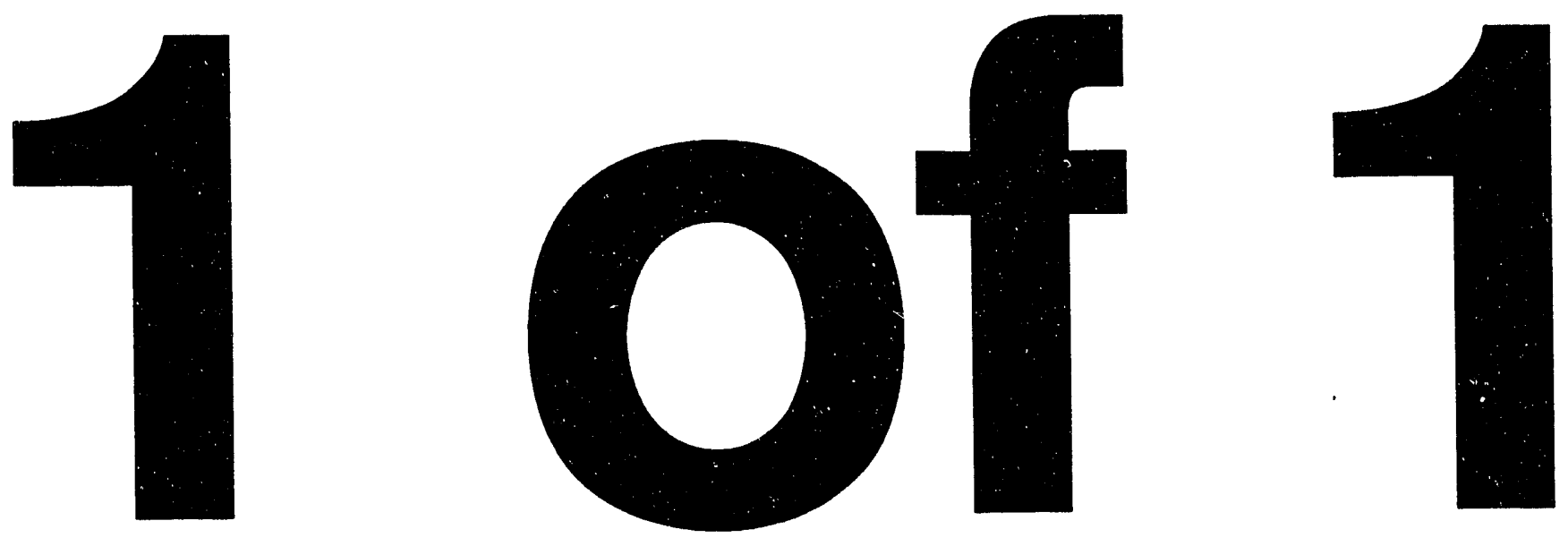
LA-UR- 93-2290
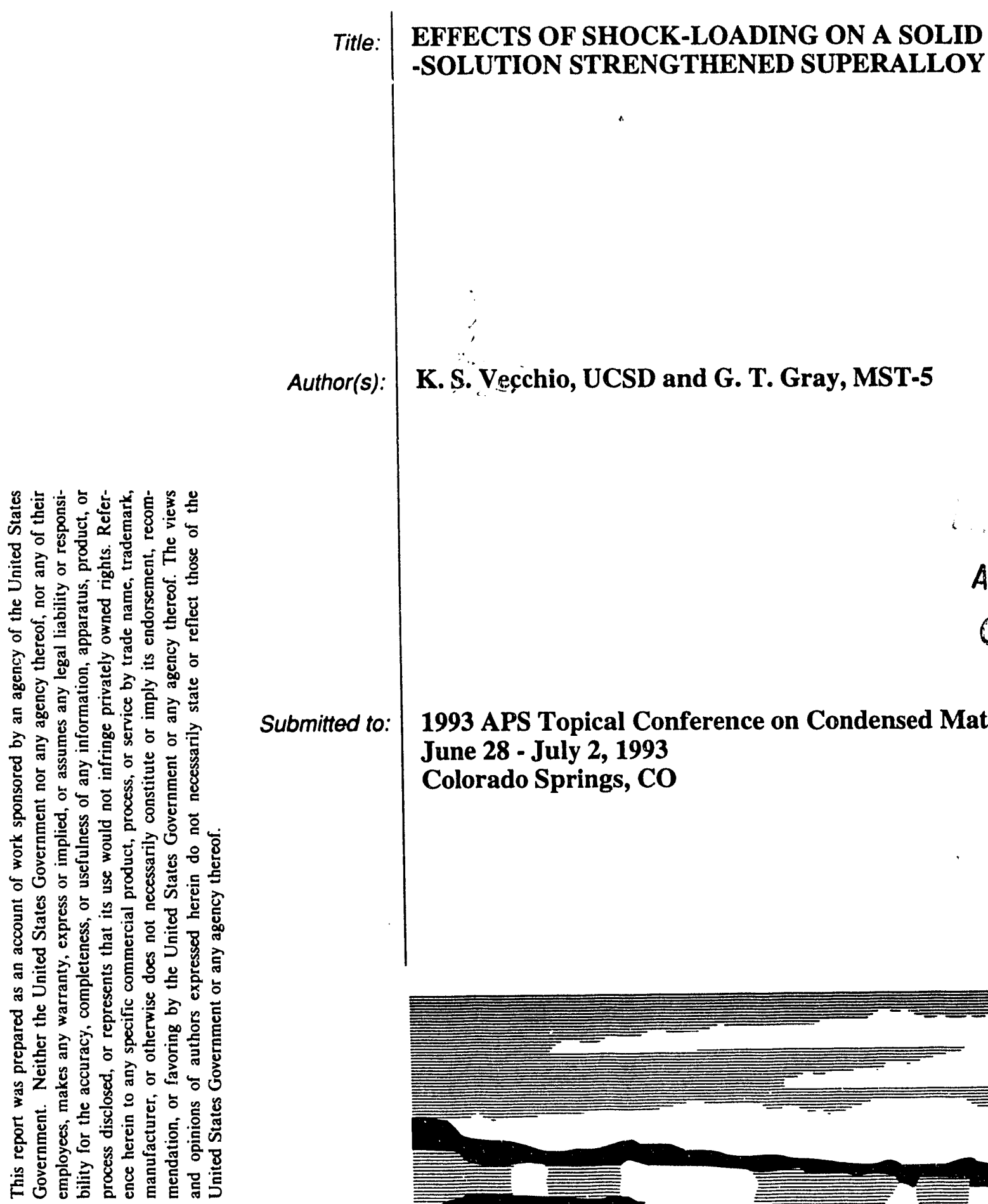

Author(s):

Submitted to:

1993 APS Topical Conference on Condensed Matter

June 28 - July 2, 1993

Colorado Springs, CO

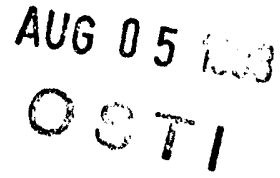

K. S. Vecchio, UCSD and G. T. Gray, MST-5

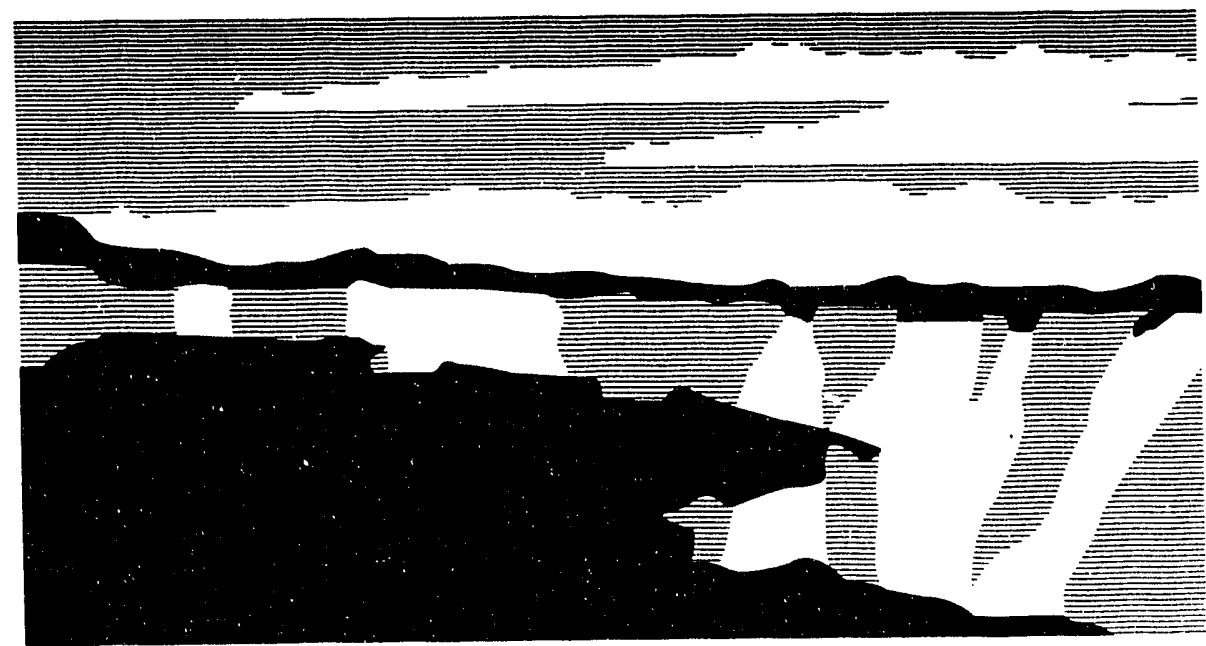

NATIONAL LABORATORY

Los Alamos National Laboratory, an affirmative action/equal opportunity empldyer, is operated by the University of California for the U.S. Department of Energy under contract W-7405-ENG-36. By acceptance of this article, the publisher recognizes that the U.S. Government retains a nonexclusive, royalty-frne lice; ise to publish or reproduce the published form of this contribution, or to allow others to do so, for U.S. Government purposes. The Los Alamos National Laboratory publish or reproduce the published form of this contribution, or to allow others to do so, for U.S. Governertment of Energy. 


\title{
EFFECTS OF SHOCK LOADING ON A SOLID-SOLUTION STRENGTHENED SUPERALLOY
}

\author{
KENNETH S. VECCHIO* and GEORGE T. GRAY, III', \\ *Dept. of AMES, UC San Diego, 9500 Gilman Dr., La Jolla, CA 92093-0411 \\ †́Los Alamos National Lab., Los Alamos, NM, 87544
}

Ni-based HAYNES ${ }^{\circledR} 230^{\text {TM }}$ ALLOY has been studied to determine the effect of shock loading on the postshock quasistatic and dynamic mechanical response, and microstructural evolution. The compression properties of this material was studied in both the as-received and shock-loaded conditions at strain rates from $10^{-3} / \mathrm{s}$ to $3000 / \mathrm{s}$, and 77 and $293 \mathrm{~K}$. Damage evolution was documented via TEM, and correlated with the observed mechanical response. Changes in the deformation mechanisms and second phase distributions resulting from the shock pre-straining and subsequent testing are correlated with changes in the strain hardening behavior of the materials. Comparison of these results with shock loading results on pure $\mathrm{Ni}$ revealed distinct differences in strengthening and defect storage mechanisms.

\section{INTRODUCTION}

To date most research on shock-loading effects in FCC materials has been directed at either pure metals or metal alloys strengthened by single element solid solutions or precipitates. Shock-loaded fcc metals and alloys have been repeatedly shown to exhibit increased defect storage, and concurrent higher hardening, behavior in reload tests after shock recovery compared to the same metal deformed at low strain rate to an equivalent strain level[1-3]. By comparison relatively little work has probed the response of more complex, engineering alloys which derive their mechanical properties through a combination of strengthening mechanisms.

In the 1970's and early 1980's a new generation of solid-solution strengthened superalloys was introduced with the goal of approaching the strength of the best cobalt-based alloys, with cobalt additions either reduced or eliminated. An example of this effort, and the subject of the present study is HAYNES $\otimes 230^{\mathrm{TM}}$ Alloy (hereafter 230 alloy). which is based on the $\mathrm{Ni}$-Cr-W system. 230 alloy is solid-solution strengthened primarily by tungsten, but like alloy $\mathrm{X}$ and cobalt-based HAYNES\& $188^{\mathrm{TM}}$ Alloy, also relies to a large extent on carbide precipitation strengthening.

The primary solid-solution element in 230 alloy is tungsten. Tungsten was selected in favor of refractory elements such as molybdenum because of its larger atomic diameter (13\% greater than nickel) and lower diffusivity in nickel. Tungsten also lowers the stacking fault energy (SFE) of nickel thus restricting cross slip of dislocations. Carbides are important contributors to the overall strengthening observed in these alloys, perhaps to a greater degree than solid-solution strengthening.

The purpose of this study was to investigate the effect of shock-loading on the mechanical properties of 230 alloy, and to correlate these properties to the microstructural chinges and substructure evolution as a function of strain rate and test temperature.

\section{EXPERIMENTAL PROCEDURE}

230 alloy in the form of hot-rolled bar was produced at Haynes International, Kokomo, IN (Heat Number 8305-9-7178). The chemical composition of this alloy is given in Ref. 4, along with the hot-rolling conditions. Shock recovery experiments were performed at New Mexico Tech., Socorro, NM using shock recovery techniques described elsewhere [5]. Samples were explosively shock-loaded to a shock pressure of 55 $\mathrm{GPa}$ for a $1.4 \mu \mathrm{s}$ pulse duration. Compression samples were EDM machined from the asreceived bar stock and shock recovered samples. Compression tests were conducted at strain rates ranging from 0.001 to $3000 \mathrm{~s}^{-1}$, at both room temperature $(293 \mathrm{~K})$ and liquid nitrogen temperature $(77 \mathrm{~K})$. Samples for transmission 
electron microscopy (TEM) were also sectioned from the recovered samples and observed using a CM-30 operating at $300 \mathrm{kV}$.

\section{RESULTS AND DISCUSSION}

Figure 1 shows a TEM micrograph of the starting microstructure of 230 alloy processed at $1121^{\circ} \mathrm{C}$. The microstructure consists of grains $\sim 20 \mu \mathrm{m}$ in diameter, which contain some annealing twins, large $\mathrm{M}_{6} \mathrm{C}$ carbides and smaller $\mathrm{M}_{23} \mathrm{C}_{6}$ carbides. The presence of the annealing twins is indicative of an FCC matrix having a low stacking fault energy, resulting frum the W solidsolution addition.

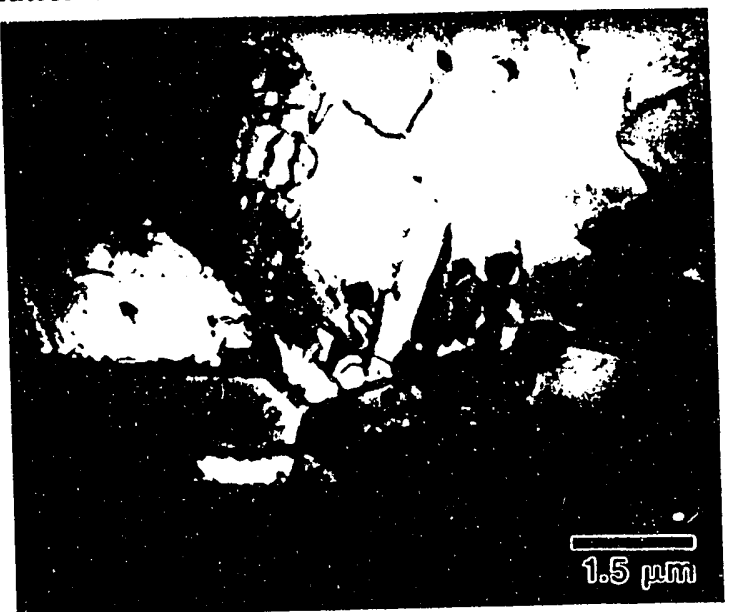

Figure 1. TEM micrograph showing the initial microstructure, particularly the dislocation substructure.

Figure 2 presents plots of the true stress-true strain response of 230 alloy at strain rates of $0.001 / \mathrm{s}$ and $3000 / \mathrm{s}$, each at temperatures of $293 \mathrm{~K}$ and $77 \mathrm{~K}$. The most striking aspects of these curves is the strong dependence of the yield strength on strain rate and temperaturi, as well as the apparent dependence of strain hardening rate on strain rate.

Figure 3 is a TEM micrograph of the asraceived 230 alloy following deformation at $77 \mathrm{~K}$ and $3000 / \mathrm{s}$ strain rate. The propensity for coarse planar slip was found to increase with increasing strain rate and decreasing temperature, with the most pronounced example shown here. Following low strain rate-room temperature testing, the dislocation substructure was clearly more homogeneous, although still planar in nature consistent with the low SFE of 230 alloy.

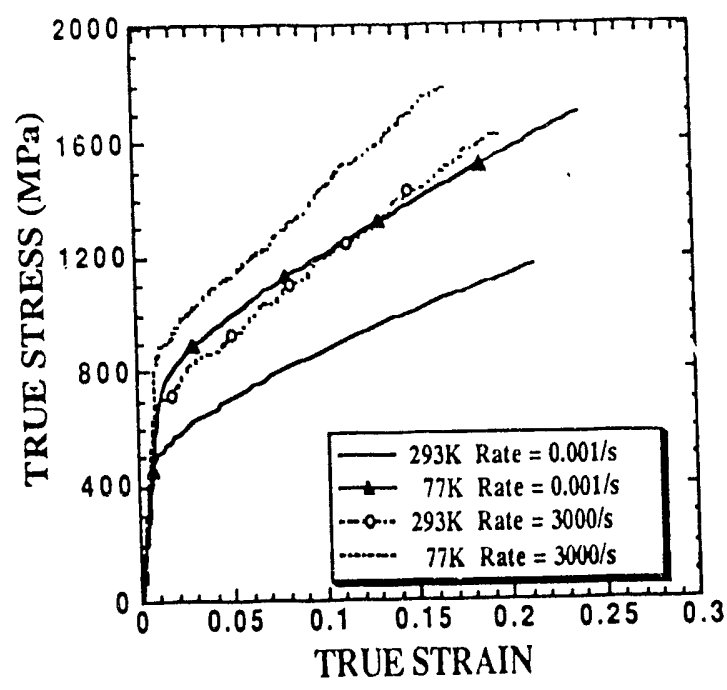

Figure 2. True stress-true strain responses of asreceived 230 alloy.

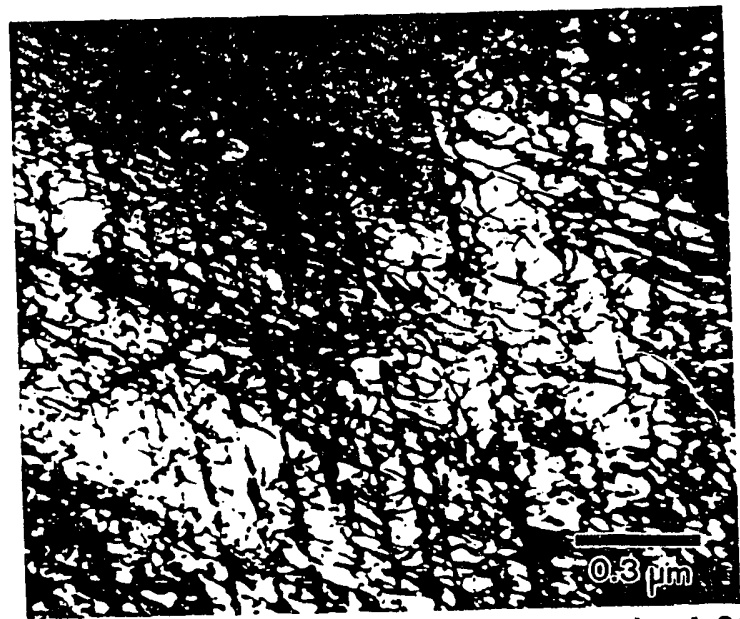

Figure 3. TEM micrograph of as-received 230 alloy deformed at $77 \mathrm{~K}$ and $3000 / \mathrm{s}$ showing planar dislocation arrays.

Figure 4 is a TEM micrograph showing the dislocation substructure and microbands introduced as a results of the shock-loading. The number of microbands varied from grain to grain, and Figure 4 represents a typical density observed; isolated deformation twins were also observed.

Figure 5 presents the reload true stress-true strain response for the shock-recovered 230 alloy material. The material shows a significant increase in yield strength for each test condition compared to the unshocked, as received 230 


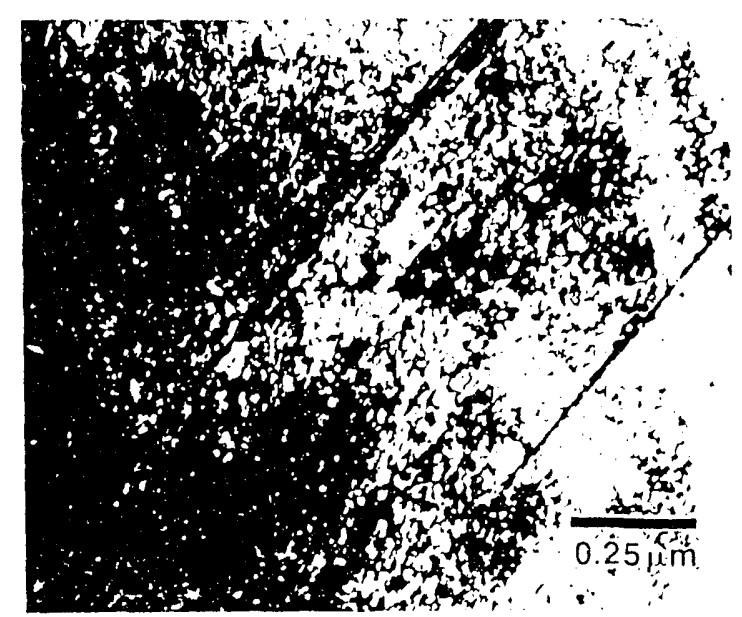

Figure 4. TEM micrograph of shock-loaded 230 alloy showing dislocation debris and microbands.

alloy. Additional tests were conducted, although not shown, in which compression samples were remachined to renove any slight barreling, reloaded to an additional $20 \%$ strain and the process repeated. In those tests performed at $77 \mathrm{~K}$ and $300(0) / \mathrm{s}$. conducted in the manner described above, 230 alloy exhibited sustained work-hardening to a strength level approaching 2.6 GPa at a true strain of $\sim 1$, followed by catastrophic shear failure. At that point, the ratio of flow stress to elastic modulus approaches $1 / 80$.

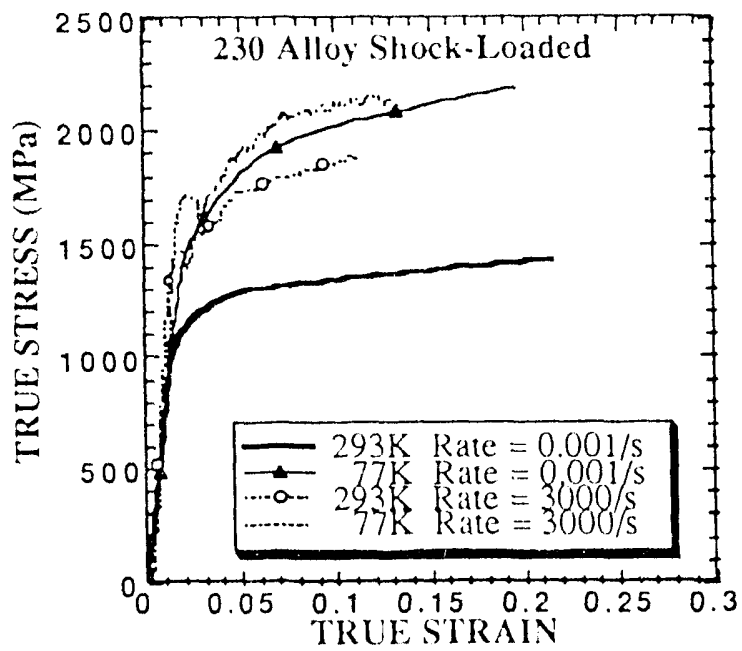

Figure 5. Reload true stress-true strain responses of shock-loaded 230 alloy.

In general, the microstructures of the reloaded shocked specimens were very similar to each other, whth the remerence of planar disteration arrays. The most distinct change in the microstructure from the as-shocked condition was the presence of very fine scale twins. The greatest density of these microtwins was found in the $0.001 / \mathrm{s}-293 \mathrm{~K}$ reload sample (see Figure 6). The microtwins were present in almost every grain of this cample, and may cxplain the reduced hardening rate observed for this sample during the reload lests, see ligure 5.

Figure 7 shows a plot of the quasi-statically loaded stress-stain response of the as-received 230 alloy and the reload stress-strain curve for the shocked 230 alloy. The reload shock curve in Figure 6 has been offect with respect to the asreceived 230 alloy response by the transient strain in the shock defined as $4 / 3 \mathrm{in}\left(\mathrm{V} / \mathrm{V}_{\mathrm{o}}\right)$, where $V$ and $V_{0}$ are the final and initial volumes of 230 alloy during the shock cycle. Also shown in this figure are results from a similar study on pure nickel shocked 1010 GPa [6] showing a sianificant increase in the reload yield strength compared to the annealed material deformed to an equivalent strain. Contrary to the previous results for pure $\mathrm{Ni}$, Ni-based 230 alloy shocked to 55 GPa does not exhibit an increased shock hardening responie compared to the 230 alloy quasi-statically defimed.

Figure 7 also shows the significant increase in strength level on 230 alloy compared to pure $\mathrm{Ni}$, as well as the significantly higher strain hardening rate for 230 allo; in both the as-received alloy and the shock reccivered material. The influence of multiple strengthening mechanisms is clearly evident from the absolute strength levels achieved by these two different nickel-based materials.

Comparison of the influence of shock loading on the mechanical response of pure $\mathrm{Ni}$ and $\mathrm{Ni}$ based 230 alloy reveals that the ability to increase the defect storage capacity of each material must be linked to stacking fault energy (SFE) differences. The higher SFE pure $\mathrm{Ni}$ is capable of storing a comparatively higher density of defects as a result of the shock loading, than it achieved through normal fuasi-static deformation to equivalent strains. In 230 alloy, although the total defect storage capicity is significantly higher than for pure $\mathrm{Ni}$, the amount of hardening achieved by shock loading was no greater than that which would be attained by normal quasi-static deformation. These results suggest that systematic studies of the influence of SFE on 


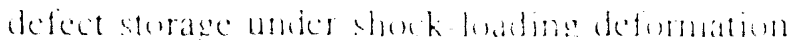

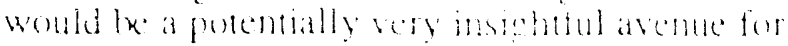
future rescarch

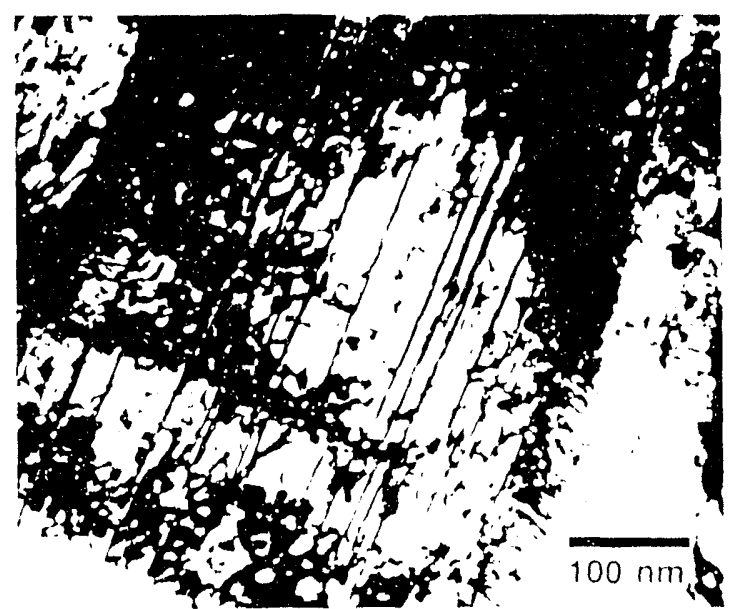

Figure 6. Tl:M micrograph of the showe luaded 230 alloy reloaded at a strain rate of (). $(K) 1 / \mathrm{s}$ and $293 \mathrm{~K}$

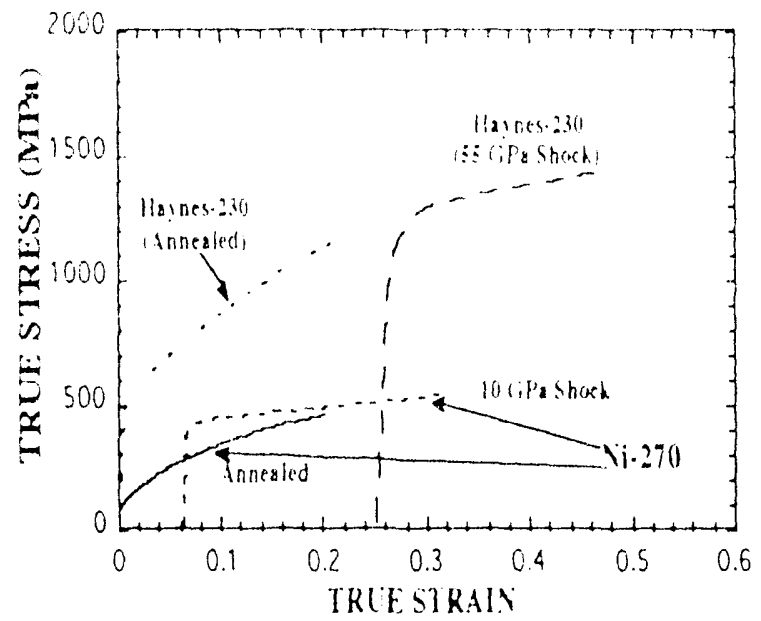

Figure 7. Comparison of as-received and shockloaded 230 alloy with reload curve of shocked sample offset by transient shock strain. The results from a similar study of pure $\mathrm{Ni}$ are also plotted.

\section{CONCLUSIONS}

Based on a study of the shock-loading and substructure evolution response of a $\mathrm{Ni}$-based superalluy (HAY NISS 230 alloyl, the following conclusions can be drawn: l) substructure

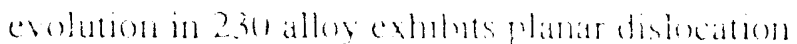
array, which is exacerbated by increasmes stam

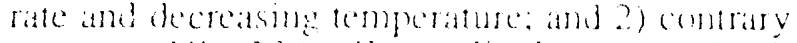
(1) pure $\mathrm{Ni}, 230$ alloys displays no shock enhanced defect storage duc to the hu cros slip propensity resulting from the lower STl: due to W alloy additions.

\section{ACKNOWIIII) IN11:NTS}

KSV acknowledges support by the U.S. Amy Research Office though a URI at UCSD contract \#DAALO3-92-(B-()108 and CIT 3 acknowledges suppor by the U.S. Dept. of Energy.

\section{RIEFERENCIS}

11) G.E. Dieter, in Response of Metals to High Velocity beformation, Interscience Publishers, New York, pp. 4(19)-4.5 (1961).

12] L.E. Murr, in Shock Haves and High Strain Rate Phenomena in Metals, (ed. by M.A. Meyers and L.L. Murr) Penum Press, N.Y'., p. $697(1981)$.

13] G.T. Gray III, in High Pressure Shock Compression of Solids, (ed. by J.R. Asay and M. Shahinpoor) N.Y : Springer-Verlag, ch. 6, (1993).

14] K. S. Vecchio, M. F. Pizparick, and D. Klarstrom, submitted to Metall. Trans., 1993.

[5] Meyers, M. A., I. W. Meyer, K. S. Vecchio, and U. Andrade, "High Strain, High StrainKate Deformation of Copper," Joumal De Physique IV, Colloque C3, suppl. au Joumal de Physique III, Oct. 1991, 1, pp. 11-17.

16] P.S. Follansbee and G.T. Gray III, Int. J. Plasticity, 7, pp. 651-660 (1991). 

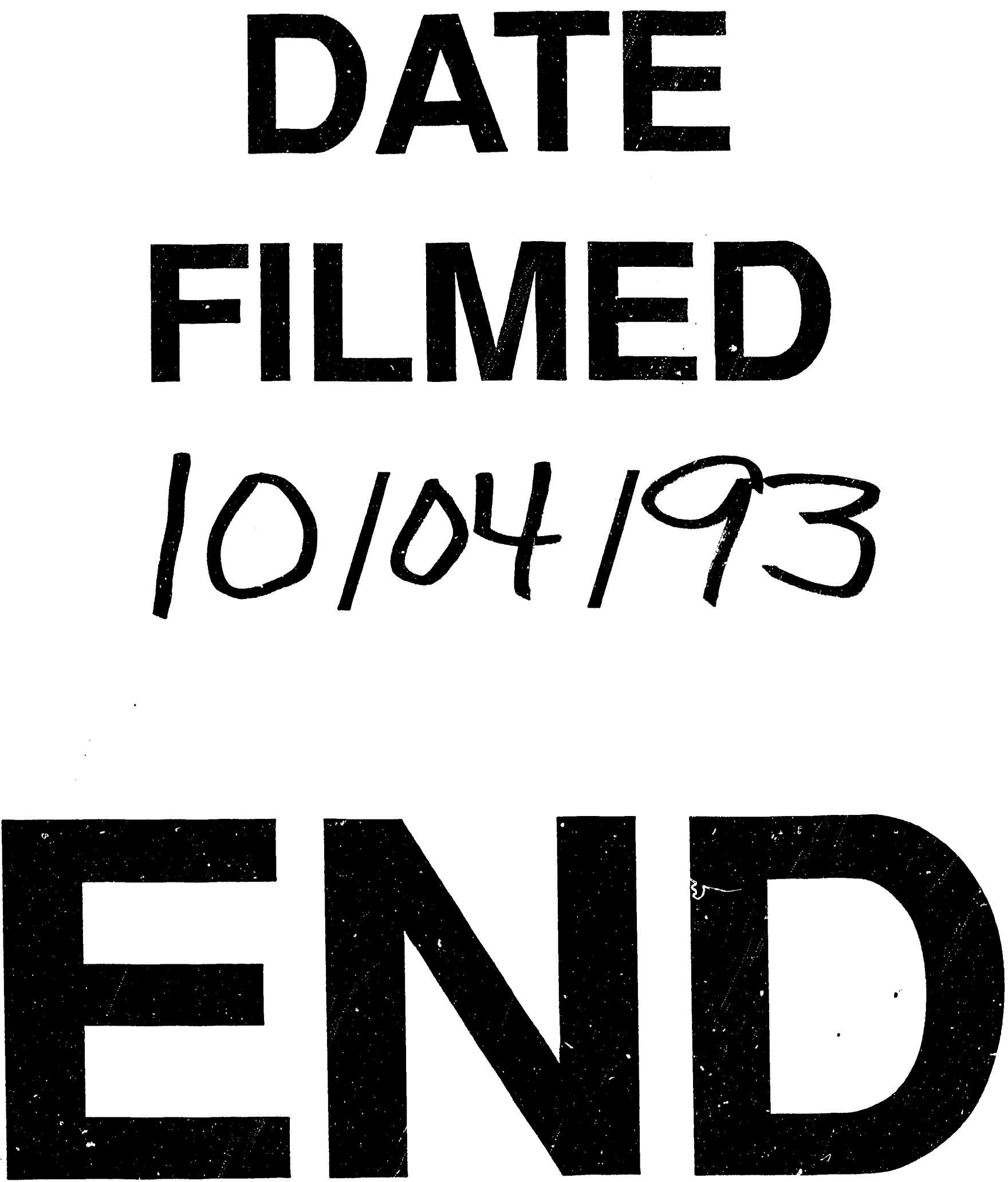
